\title{
Fremalaric

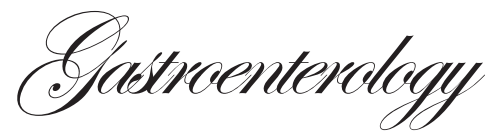 \\ Clinical and biochemical factors associated with biliary atresia
}

\author{
Ira Shah, Susmita Bhatnagar, Harshal Dhabe
}

\section{ABSTRACT}

Department of Pediatric Hepatobiliary Clinic,

B. J. Wadia Hospital for Children, Parel, Mumbai - 400012, India

\section{Correspondence:}

Dr. Ira Shah

Email:irashah@pediatriconcall.com
Aim: To determine the clinical and biochemical factors associated with biliary atresia. Methods: This retrospective study was carried at the Pediatric Hepatobiliary Clinic, of a tertiary care referral center, from May 2005 to April 2006. Thirty-three infants with neonatal cholestasis were enrolled. All patients were evaluated by detailed history and clinical examination. Patients diagnosed with biliary atresia on intra-operative cholangiogram and liver biopsy underwent the Kasai operation. Clinical and biochemical factors predictive of biliary atresia were determined.

Results: Seventeen infants $(51.5 \%)$ had neonatal hepatitis, $(42.4 \%)$ biliary atresia and two $(6.1 \%)$ neonatal sepsis. Clay colored stools was the only clinical feature suggestive of biliary atresia which was seen in 11 biliary atresia children (79\%) and was statistically significant $(\mathrm{p}=0.05)$. No other biochemical markers were suggestive of biliary atresia, such as alkaline phosphatase $(\mathrm{p}=0.10)$ or gamma glutamyl transferase (GGTP) $(\mathrm{p}=0.64)$. On follow-up 6 patients $(43 \%)$ with biliary atresia developed chronic liver disease and two patients (14\%) died of their disease, whereas $41 \%$ patients with neonatal hepatitis made successful recovery. $(\mathrm{p}=0.02)$ Conclusion: Presence of clay colored stools is a predictive marker for biliary atresia and should be used as one of the markers for urgent cholangiogram, since most of the children with biliary atresia go on to develop chronic liver disease.

KEYWORDS: biliary atresia, clinical features, predictors

\section{Introduction}

Neonatal cholestasis syndrome (NCS) is a group of hepatobiliary disorders occurring within the first three months of life. ${ }^{1}$ NCS constitutes $30 \%$ of hepatobiliary disorders in India. ${ }^{2}$ The two most common causes are biliary atresia (BA) and idiopathic neonatal hepatitis accounting for $50-70 \%$ of cases. ${ }^{3}$ BA is a cholangiodestructive disease of both intra- and extrahepatic parts of the biliary system and if left untreated, leads to cirrhosis and liver failure. It is the commonest indication for pediatric liver transplant. ${ }^{4}$ Kasai portoenterostomy introduced almost 50 years earlier in Japan remains the surgical treatment of choice to restore bile flow and alleviate jaundice. In infants with BA, delay in presentation and diagnosis is the single most important factor that results in poor prognosis in developing countries. ${ }^{5}$ Investigations such as ultrasonography, liver biochemistry, duodenal intubation and measurement of intraluminal bile, endoscopic retrograde cholangiogram (ERCP), magnetic cholangiopancreaticogram (MCRP) and HIDA scan have been used for diagnosis but may not give accurate results. 
Operative cholangiography remains the key investigation in demonstrating biliary patency ${ }^{4}$ and diagnosing biliary atresia. Although percutaneous liver biopsy has been found to have a 90-95\% diagnostic accuracy for BA, ${ }^{6}$ presenting with portal tract inflammation and bile ductile plugging and proliferation, and/or fibrosis; but facilities for emergency and accurate reporting of histopathological specimens may not always be available and sometimes liver biopsy may not be absolutely indicative of biliary atresia. Thus, we undertook a study to demonstrate clinical or biochemical markers which may point towards the diagnosis of biliary atresia so that urgent cholangiography and surgical intervention can be undertaken.

\section{Methods}

All children referred to our Pediatric Hepatobiliary Clinic with neonatal cholestasis were enrolled in the study. They underwent a detailed history and a thorough clinical examination. To determine the etiology of neonatal cholestasis: TORCH titres, urine for reducing substances, HIDA scan and/ or intra-operative cholangiogram with liver biopsy was done. Additional tests including serum alpha-1 antitrypsin, urine aminoacidogram, urine organic acids, and echocardiography were done as and when required. In addition, patients were tested for liver function tests, and ultrasonography of the abdomen and stool for stercobilinogen. CMV infection was diagnosed on the basis of a positive CMV IgM or four-fold rise in the CMV IgG titres after 2-4 week interval or a positive urine CMV or inclusion bodies on liver biopsy. Biliary atresia was diagnosed on the basis of typical liver biopsy pathology and absence of dye excretion on intra-operative cholangiogram after ruling out other causes of obstructive jaundice. All patients were treated with fat soluble vitamins and ursodeoxycholic acid in cholestatic doses. Patients who were diagnosed to have biliary atresia on intra-operative cholangiogram and liver biopsy underwent a Kasai operation. All children were followed up for a period of 3-6 months to determine the outcome of their neonatal cholestasis. Clinical and biochemical factors predictive of biliary atresia were determined after appropriate data analysis. Appropriate clinical and laboratory factors were analyzed by ANOVA-1 and Chi square test.

\section{Results}

Thirty-three infants with neonatal cholestasis were enrolled in the study. The mean age of presentation was 107 days with a median of 75 days ( $96.5 \% \mathrm{CI}=60$ to 90 days) and the presentation period ranged from day 1 of life to day 635 . The male to female ratio was 25:8. All children (100\%) had jaundice with a mean onset at 16.2 days and median being since birth (97.1\% CI = birth to 15 days). Nineteen children $(57.6 \%)$ had clay colored stools, with its mean onset at 16.4 days and median being since birth $(96.9 \% \mathrm{CI}=$ birth to 25 days $)$. Of these 19 children $11(79 \%)$ had biliary atresia and the proportion was statistically significant $(\mathrm{p}=0.05)$. Three mothers $(9.1 \%)$ had fever during the first trimester of their pregnancy, however none of them had any rash or lymphadenopathy. Thirty children (91\%) had hepatomegaly, $25(76 \%)$ had splenomegaly and 8 patients (24\%) had ascites. Liver biopsy was done in 14 patients and intra-operative cholangiogram was done in 13 patients of which 11 patients $(84.6 \%)$ underwent a Kasai operation. Two patients

Table 1a: Clinical and biochemical factors associated with biliary atresia

\begin{tabular}{|c|c|c|c|c|}
\hline & $\begin{array}{c}\text { Neonatal hepatitis } \\
\qquad(\mathrm{n}=17)\end{array}$ & $\begin{array}{l}\text { Biliary atresia } \\
\quad(n=14)\end{array}$ & $\begin{array}{l}\text { Neonatal sepsis } \\
\qquad(\mathrm{n}=2)\end{array}$ & p value \\
\hline Gender & Male $=13$, Female $=4$ & Male $=10$, Female $=4$ & Male $=2$ & 0.67 \\
\hline Clay coloredstools & $8(47 \%)$ & $11(79 \%)$ & $0(0 \%)$ & 0.05 \\
\hline Ascites & $3(18 \%)$ & $4(29 \%)$ & $1(50 \%)$ & 0.53 \\
\hline Splenomegaly & $12(71 \%)$ & $11(79 \%)$ & $2(100 \%)$ & 0.62 \\
\hline Raised alkaline phosphatase & $8(62 \%)$ & $10(77 \%)$ & $0(0 \%)$ & 0.10 \\
\hline Raised SGOT & $16(100 \%)$ & $13(93 \%)$ & $1(50 \%)$ & 0.02 \\
\hline Raised SGPT & $15(94 \%)$ & $14(100 \%)$ & $1(50 \%)$ & 0.02 \\
\hline Raised GGTP & $5(71 \%)$ & $5(83 \%)$ & $2(100 \%)$ & 0.64 \\
\hline Positive CMV & $6(67 \%)$ & $6(75 \%)$ & $0(0 \%)$ & 0.95 \\
\hline \multicolumn{5}{|l|}{ Follow up } \\
\hline - Chronic liver disease & $0(0 \%)$ & $6(43 \%)$ & $0(0 \%)$ & 0.02 \\
\hline - Died & $2(12 \%)$ & $2(14 \%)$ & $0(0 \%)$ & \\
\hline - Lost to follow up & $7(41 \%)$ & $4(29 \%)$ & $1(50 \%)$ & \\
\hline - Recovered & $7(41 \%)$ & $1(7 \%)$ & $1(50 \%)$ & \\
\hline - To follow up & $1(6 \%)$ & $1(7 \%)$ & $0(0 \%)$ & \\
\hline
\end{tabular}


Table 1b: Clinical and biochemical factors associated with biliary atresia

\begin{tabular}{|c|c|c|c|c|}
\hline & $\begin{array}{l}\text { Neonatal hepatitis } \\
\quad(\text { Mean } \pm \text { SD) }\end{array}$ & $\begin{array}{c}\text { Biliary atresia } \\
(\text { Mean }+\mathrm{SD})\end{array}$ & $\begin{array}{c}\text { Neonatal sepsis } \\
(\text { Mean } \pm \text { SD })\end{array}$ & p value \\
\hline Age in days & $109 \pm 86.2$ & $118 \pm 153.6$ & $15 \pm 20.5$ & 0.52 \\
\hline Onset of jaundice in days & $21.4 \pm 28$ & $12.3 \pm 22.6$ & 0 & 0.42 \\
\hline Onset of clay stools in days & $16.8 \pm 31.2$ & $16.0 \pm 24.9$ & - & \\
\hline Total bilirubin (mg/dl) & $11.4 \pm 5.1$ & $9.7 \pm 5.5$ & $16.5 \pm 12.7$ & 0.29 \\
\hline Direct bilirubin (mg/dl) & $5.4 \pm 3.0$ & $6.4 \pm 3.6$ & $7.6 \pm 3.6$ & 0.55 \\
\hline Alkaline phosphatase (IU/L) & $1151 \pm 685$ & $1361 \pm 627$ & $512 \pm 190$ & 0.22 \\
\hline SGOT (IU/L) & $198.5 \pm 118$ & $292 \pm 257$ & $55 \pm 57$ & 0.18 \\
\hline SGPT (IU/L) & $154 \pm 133$ & $167 \pm 84$ & $44 \pm 27$ & 0.36 \\
\hline GGTP (IU/L) & $160 \pm 176$ & $601 \pm 852$ & $265 \pm 124$ & 0.39 \\
\hline
\end{tabular}

succumbed to their illness and could not undergo a Kasai operation and one patient refused surgery. Seventeen patients $(51.5 \%)$ had neonatal hepatitis, $14(42.4 \%)$ had biliary atresia and two $(6.1 \%)$ had neonatal sepsis. Factors associated with biliary atresia were analyzed and are depicted in Table 1a and 1b. On follow up, 6 patients (43\%) with biliary atresia developed chronic liver disease whereas 7 patients (41\%) with neonatal hepatitis recovered, and was found to be statistically significant $(\mathrm{p}=0.02)$.

\section{Discussion}

Neonatal cholestasis syndrome (NCS) is characterized by conjugated jaundice lasting more than two weeks after birth. There is often a delay in seeking medical attention with most referrals at almost 3.5 months of age. ${ }^{2}$ In our study, too most of the patients were referred around 2.5 months of age, even though most of the children were symptomatic since birth to an average age of 16 days.

The incidence of biliary atresia in our study was $42.4 \%$, suggesting that BA is one of the most important causes of NCS in this part of India and early referral would help in timely diagnosis and treatment of these patients. Other studies have noted a lower incidence of BA in Bangladesh (25.8\%) and India (34\%). ${ }^{1,2}$ Among the general population, the incidence of BA is approximately 1 in 8-9,000 population in Japan, China and Asia and about 1 in 12-15,000 in Europe and the USA.,8 Thus it is very important that BA is diagnosed early in our parts of the world.

Among the various clinical and biochemical features, gender, degree of jaundice, age of onset of jaundice, degree of elevation of liver transaminases, alkaline phosphatase and GGTP were not diagnostic of biliary atresia. This has also been depicted in other studies ${ }^{1}$ and the national consensus report on NCS in
India has also suggested that these children should undergo percutaneous cholangiography even if the liver biopsy is suggestive of neonatal hepatitis. ${ }^{2}$ Azar et $\mathrm{al}^{9}$ have also suggested that histopathological findings of biliary atresia may be evident on liver biopsy even later in life and infants with unexplained conjugated hyperbilirubinemia and acholic stools should undergo sequential liver biopsies until clinical improvement occurs or until biliary atresia can be excluded from the differential diagnosis. Thus the presence of persistent acholic stools in an infant with NCS should raise the clinician's suspicion for BA and we would recommend even a direct cholangiogram without waiting for a liver biopsy. This would prevent delay, confusion due to differing histopathological reports and an exact diagnostic inclusion or exclusion by the cholangiogram.

Though biliary atresia has been reported to occur commonly in females, ${ }^{3}$ similar findings were not obtained in our study. It has also been reported that serum bilirubin rarely exceeds 12 $\mathrm{mg} / \mathrm{dl}$ in infants with BA whereas it may exceed $20 \mathrm{mg} / \mathrm{dl}$ in those with neonatal hepatitis $(\mathrm{NH}) .^{3}$ In our study, the mean bilirubin was $9.7 \mathrm{mg} / \mathrm{dl}$ in infants with BA and $11.4 \mathrm{mg} / \mathrm{dl}$ in those with NH. Similar findings have been reported from Bangladesh too. ${ }^{1}$ Thus, it may be difficult to differentiate BA from other causes of cholestasis by biochemical tests.

On follow-up, $43 \%$ of patients with BA had chronic liver disease and portal hypertension, whereas $41 \%$ of patients with neonatal hepatitis showed complete recovery. Untreated biliary atresia led to death. Thus timely surgical intervention is essential to ensure good prognosis as liver transplantation is still unreachable to most of the patients in our country.

Thus to conclude, biliary atresia is an important cause of neonatal cholestasis syndrome in India. Though jaundice develops early, most children are referred late to the hospital. The definitive clinical feature suggestive of biliary atresia is 
the presence of acholic stools, while other biochemical and clinical features lack specificity due to similar trends in other causes of NCS.

\section{References}

1. Bazlul Karim AS, Kamal M. Cholestatic jaundice during infancy: experience at a tertiary care center in Bangladesh. Indian $J$ Gastroenterol. 2005;24:52-4.

2. Indian Academy of Pediatrics. Pediatric Gastroenterology Subspecialty Chapter. Consensus report on Neonatal Cholestasis Syndrome. Pediatric Gastroenterology Subspecialty Chapter of Indian Academy of Pediatrics. Indian Pediatr. 2000;37:841-51.

3. Sokol RJ, Mack C, Narkewicz MR, Karrer FM. Pathogenesis and outcome of biliary atresia: current concept. J Pediatr Gastroenterol Nutr. 2003;37:4-21.
4. Davenport M. Biliary atresia: Outcome and management. Indian J Pediatr. 2006;73:825-8.

5. Yachha SK, Mohindra S. Neonatal cholestasis syndrome: Indian scene. Indian J Pediatr. 1999;66:S94-6.

6. Balistreri WF, Bove K, Ryckman FC. Biliary atresia and other disorders of the extrahepatic bile ducts. In: Suchy FJ. Sokol RJ, Balistreri WF, editors. Liver Disease in Children. Philadelphia: Lippincott Williams \& Wilkins. 2001. p. 253-74.

7. Nio M, Ohi R, Miyano T, Saeki M, Shiraki K, Tanaka K; Japanese Biliary Atresia Registry. Five- and 10-year survival rates after surgery for biliary atresia: a report from the Japanese biliary atresia Registry. J Pediatr Surg. 2003;38:997-1000.

8. McKiernan PJ, Baker AJ, Kelly DA. The frequency and outcome of biliary atresia in the UK and Ireland. Lancet. 2000;335:25-9.

9. Azar G, Beneck D, Lane B, Markowitz J, Daum F, Kahn E. Atypical morphologic presentation of biliary atresia and value of serial liver biopsies. J Pediatr Gastroenterol Nutr. 2002;34:212-5. 